\title{
Caracterização e seleção de rizóbios nativos de solos paraibanos associados à Vigna unguiculata (L.) Walp. ${ }^{1}$
}

\author{
Jardel da Silva Souza ${ }^{2}$, Adriana Ferreira Martins ${ }^{3}$
}

\begin{abstract}
Resumo: O feijão-caupi Vigna unguiculata (L.) Walp. é incluída entre as principais culturas de subsistência e com mais importância no sertão nordestino. Contudo, os cultivos praticados no estado são de baixo nível tecnológico, necessitando assim aplicações de insumos minerais industrializados, o que contribui para o encarecimento na produção. Com isso a utilização de insumos biológicos que possa substituir os químicos industrializados tem sido cada vez mais frequente na agricultura. O feijão caupi é capaz de estabelecer simbiose e nodular com diversas espécies de bactérias do grupo rizóbio, com essa baixa especificidade da cultura em relação ao microssimbionte apresenta-se como um fator limitante à exploração desta tecnologia. Por esta razão, é importante estudar estratégias que possa avaliar a composição e a contribuição de estirpes de rizóbios nativos do solo onde se pretende introduzir o inoculante. Diante do exposto, objetivou-se selecionar isolados de rizóbios nativos de solos agrícolas do município de Areia $(\mathrm{PB})$, para plantas de feijão-caupi, como também caracterizar e avaliar os isolados de rizóbios obtidos, tendo como comparação a estirpe recomendada 03-84-6/2010 UFLA. Os experimentos com plantas foram conduzidos em ambiente semi protegido do DSER. De acordo com os resultados obtidos após os 40 dias, pode-se constatar que todos os tratamentos estavam com nódulos, com exceção da segunda repetição do tratamento sem nitrogênio. E foram obtidos oito grupos distintos de rizóbios nativos. Conclui-se que os solos da zona úmida da Caatinga, em Areia (PB), possuem bactérias nitrificantes nativas capazes de nodular e fixar nitrogênio.
\end{abstract}

Palavras-Chave: Bactérias nitrificantes nativas; caracterização morfológica de bactérias nitrificantes; Bioma Caatinga; simbiose planta-bactéria; microbiologia do solo.

\section{Characterization and selection of native rihzobia of Paraíba soils associated with Vigna unguiculata (L.) Walp.}

\begin{abstract}
The cowpea Vigna unguiculata (L.) Walp. this beanis the main subsistence crop of these regions, with more importance in the northeastern Sertão. However, the practiced cultivations in the state use low technological level. In this way, we need applications of industrialized mineral inputs, which contributes to the yield increase. With that, the use of biological inputs that can replace industrialized chemicals has been increasingly frequent in agriculture. The cowpea is able to establish symbiosis and nodulate with several species of bacteria of the rhizobia group, with this low specificity of the crop in relation to the microsymbionte, it is a limiting factor to the exploitation of this technology. For this reason it is important to study strategies that can evaluate the composition and distribution of rhizobia strains native to the soil where it is intendedto apply the inoculant. Based on that, the objective of this study was to select isolates of native rhizobia from agricultural soils of the city of Areia (PB), for cowpea plants, and to characterize and evaluate the rhizobia isolates obtained, comparing to the recommended strain 03-84 -6/2010 UFLA. The tests were carried out in a protected environment of the DSER. After 40 days, according to the obtained results, it could be found that all treatments presented nodules, except the second replication of the treatment without nitrogen. Eight different groups of native rhizobia were obtained. It can be concluded that the humid zone of Caatinga, in Areia (PB), has native nitrifying bacteria able to nodulate and fix nitrogen.
\end{abstract}

Keywords: Native nitrifying bacteria; morphological characterization of nitrifying bacteria; Caatinga Biome; plant-bacterial symbiosis; microbiology of soil.

${ }^{1}$ Submetido em 13/03/2019 e aprovado em 01/12/2019;

${ }^{2}$ Programa de Pós-Graduação em Agronomia, Universidade Federal da Paraíba, Areia, Paraíba, Brasil; E-mail: jardel.souza@live.com ORCID: 0000-0003-1853-0934;

${ }^{3}$ Programa de Pós-Graduação em Ciência do Solo, Universidade Federal da Paraíba, Areia, Paraíba, Brasil; E-mail: biol.adriana@gmail.com ORCID: 0000-0002-8960-3101

Agropecuária Técnica, Areia-PB, v. 40, n. 3-4, p. 71-81, 2019

https://doi.org/10.25066/agrotec.v40i3-4.44892 


\section{Introdução}

A produção de feijão-caupi nas regiões Nordeste e Norte é feita por empresários e agricultores familiares que ainda utilizam práticas tradicionais (Freire Filho et al., 2011). Contudo, os cultivos praticados no estado da paraíba são de baixo nível tecnológico (Oliveira Júnior et al., 2002). Assim, necessitando das aplicações de insumos minerais industrializados, o que contribui para o encarecimento na produção, como também, os impactos advindos de práticas realizadas sem respeitar a necessidade da cultura e a fertilidade do solo. Deste modo, a utilização de insumos biológicos como forma de substituição dos industrializados tem sido cada vez mais utilizada na agricultura (Melo \& Zilli, 2009).

Entretanto, não se tem muitos estudos sobre a comunidade de bactérias nitrificantes para a cultura na zona úmida do bioma Caatinga. Além disso, o feijão-caupi é capaz de estabelecer simbiose e nodular com diversas espécies de bactérias do grupo rizóbio, incluídos gêneros como Azorhizobium, Burkholderia, Bradyrhizobium, Mesorhizobium, Rhizobium, Sinorhizobium, entre outros (Neves \& Rumjanek, 1997; Willems, 2006; Zilli et al., 2006; Zhang et al., 2007; Moreira, 2008)., Essa baixa especificidade da cultura em relação ao microssimbionte apresenta-se como um fator limitante à exploração desta tecnologia, tendo em vista que as bactérias nodulantes presentes no solo, além de ser competitivas e estar em maior número, apresentam uma eficiência variável na fixação biológica do nitrogênio (FBN) (Thies et al., 1991; Hara \& Oliveira, 2007), dificultando a introdução de inoculantes contendo rizóbios eficientes, uma vez que as bactérias indígenas ou nativas são mais adaptadas e competitivas, deslocando rapidamente as estirpes dos inoculantes dos sítios de infecção (Santos et al., 2007).

Além do reconhecimento entre o simbionte e o hospedeiro por meio de trocas de sinais bioquímicos, para se estabelecer a simbiose também se deve levar em consideração fatores abióticos (Lieven-Antoniou \& Whittan, 1997), como as condições do solo que são muito importantes e exercem influência sobre estes seres. Fatores como acidez do solo, salinidade, deficiências ou excesso de minerais, estresse hídrico, variações de temperatura e também a quantidade de nitrogênio inorgânico no solo, podem afetar a interação entre a leguminosa e o rizóbio, que levará a interferência do fluxo de nitrogênio (Moreira \& Siqueira, 2006). Desta forma a identificação destas características em isolados de rizóbio com elevada capacidade de FBN é importante para seleção destes microrganismos, que sejam resistentes e adaptados a estas condições.

A FBN vem se mostrando indispensável na sustentabilidade da agricultura brasileira, tendo em vista a disponibilização de nitrogênio para as culturas com um baixo custo econômico e também com baixo impacto ambiental (Hungria et al., 2007). Sendo assim, com o presente estudo objetivou-se a obtenção, caracterizar e seleção de isolados de bactérias nitrificantes nativas associadas à Vigna unguiculata da zona úmida do Bioma Caatinga. Assim como, avaliar a eficiência na fixação simbiótica de nitrogênio destes microrganismos oriundos de solos do município de Areia (Paraíba).

\section{Material e Métodos}

O local de estudo, município de Areia Paraíba, está localizado na microrregião geográfica do brejo paraibano a $574 \mathrm{~m}$ de altitude (Lat. $6^{\circ} 58^{\circ e}$; Long. $35^{\circ} 41^{\text {ec }}$ ), com temperatura média anual de $24^{\circ} \mathrm{C}$,pluviosidade média anual de $1400 \mathrm{~mm}$, umidade relativa média de $80 \%$ e de, acordo com Koppen (1936), o clima do tipo As, ou seja, clima tropical, semi-umido, enquanto Thornthwaite (1948) classifica o clima da região como B1 Ra ,ae, que é um clima úmido, apresentando pouca deficiência de umidade, megatérmico, com pequena variação de temperatura.

\subsection{Locais de amostragem}

Foram coletadas duas amostras de solos onde anteriormente tinha sido cultivado o feijão-caupi no município de Areia, com vistas à obtenção do maior número possível de isolados de rizóbios autóctones capazes de nodular esta espécie. Uma amostra foi coletada na Estação Experimental Chã de Jardim - área de pousio de 10 anos e, a outra amostra foi do Distrito de Mata Limpa coordenadas: Altitude $563 \mathrm{~m}, \mathrm{~S} 06^{\circ} 54^{\prime} 20,8^{\prime \prime}, \mathrm{W}$ $35^{\circ} 40^{\prime} 52,0^{\prime}$ ', em que a prática se dá sem insumos químicos; ambos os solos são classificados como Latossolo Amarelo Distrófico húmico (Embrapa, 2013). Amostras dos solos foram enviadas ao

Agropecuária Técnica, Areia-PB, v. 40, n. 3-4, p. 71-81, 2019

https://doi.org/10.25066/agrotec.v40i3-4.44892 
Laboratório de Análise de Fertilidade do Solo, do Departamento de Solos e Engenharia Rural, da Universidade Federal da Paraíba para determinação das características químicas (Tabela 1).

Tabela 1 Caracterização química dos solos utilizados na obtenção de nódulos

\begin{tabular}{|c|c|c|c|c|c|c|c|c|c|c|c|c|c|c|}
\hline \multirow{2}{*}{ Solo } & $\mathrm{pH}$ & $\mathrm{P}$ & $\mathrm{K}$ & $\mathrm{Na}^{+}$ & $\mathrm{Ca}^{2+}+\mathrm{Mg}^{2+}$ & $\mathrm{Ca}^{2+}$ & $\mathrm{Mg}^{2+}$ & $\mathrm{Al}^{3+}$ & $\mathrm{H}^{+}+\mathrm{Al}^{3+}$ & $\mathrm{C}$ & MO & SB & CTC & V \\
\hline & & \multicolumn{2}{|c|}{$---m g d^{-3}--$} & & & cmolc & $m^{-3}$ & & & \multicolumn{2}{|c|}{-----g Kg---- } & \multicolumn{2}{|c|}{ cmolc $\mathrm{dm}^{-3}$} & $\%$ \\
\hline ML & 5.5 & 11,3 & 95,2 & 0,06 & 1,35 & 0,73 & 0,62 & 0,3 & 4,7 & 9,85 & 17 & 1,66 & 6,36 & 26 \\
\hline $\mathrm{CJ}$ & 5,2 & 3,12 & 34,7 & 0,07 & 0,85 & 0,55 & 0,3 & 0,45 & 7,34 & 15,7 & 27,1 & 1,01 & 8,35 & 12,1 \\
\hline
\end{tabular}

ML: Mata limpa; CJ: Chã de jardim

\subsection{Obtenção dos nódulos}

Para a obtenção de nódulos a partir das amostras de solo, foi realizado um experimento com a inoculação de plântulas de Vigna unguiculata com uma suspensão dos solos amostrados em um ambiente semi-protegido. As sementes foram previamente desinfestadas, sendo em seguida colocadas para germinação em vasos. Cinco sementes foram plantadas em cada vaso do tipo "Leonard" (Vincent, 1970), contendo, como substrato na parte superior, uma mistura de vermiculita e areia (2:1), e solução nutritiva (Sarruge, 1975) estéril sem nitrogênio, pH 6,0, na parte inferior dos vasos. Após o semeio, os vasos foram inoculados com uma alíquota de $10 \mathrm{~mL}$ da suspensão de cada amostra de solo em solução salina $(\mathrm{NaCl} \quad 0,085 \mathrm{~mL})$ esterilizada, sendo utilizado três repetições para cada amostra de solo. Também, foram utilizados dois tratamentos como controle, sendo um com solução nutritiva contendo nitrogênio e sem inoculação, e outra sem inoculação e sem nitrogênio, toda a solução utilizada em todos os tratamentos durante o experimento foram anteriormente autoclavada a $121^{\circ} \mathrm{C}$ por 15 min para evitar contaminação. Aos quatorze dias de crescimento, foi realizado o desbaste deixando-se duas plântulas por vaso. A solução nutritiva dos vasos foi completada a cada três dias, intercalada com a adição de água destilada esterilizada. Ao total foram cinco tratamentos com três repetições cada e duas plantas por vaso. Após 40 dias da inoculação, foi avaliada a nodulação, considerando-se tamanho e coloração dos nódulos, e coletando-se os nódulos das plantas para o isolamento dos rizóbios no laboratório.

\subsection{Isolamento dos rizóbios autóctones}

$\mathrm{O}$ isolamento dos rizóbios foi executado a partir dos nódulos radiculares de Vigna unguiculata que foram obtidos das plantas inoculadas com suspensão de solo, cultivadas em ambiente semi-protegido.

No laboratório, os nódulos foram previamente desinfestados; após a desinfestação, os nódulos foram esmagados com um bastão de vidro e inoculados em placas de petri contendo meio ágar levedura-manitol com vermelho congo (LMV) (Vincent, 1970) visando-se a obtenção de colônias bacterianas isoladas. Estes isolados foram re-inoculados em placas com meio LMV sucessivamente para purificação da cultura, até a obtenção de colônias com características homogêneas e persistentes. Para se ter uma boa visualização das colônias para caracterização, cada isolado foi diluído $6 \mathrm{x}$ em solução salina e reinoculados para a caracterização morfológica.

\subsection{Caracterização morfológica dos isolados de rizóbios}

A avaliação da morfologia das colônias foi realizada a partir da inoculação dos isolados diluídos 6x, em placas de Petri contendo meio de cultivo LMV, com pH 6,8 a partir de 24 horas da incubação a $28^{\circ} \mathrm{C}$, sendo avaliado o tamanho, forma, elevação, bordas (lisa ou irregular), superfície (lisa ou granular), cor, densidade ótica (opaca, translúcida, transparente) e consistência ao toque com alça (gomosa, pastosa, viscosa ou aquosa). Também foi realizado teste de Gram.

\subsection{Bioensaio de eficiência dos isolados na fixação simbiótica de nitrogênio}

Os isolados foram selecionados levando em consideração a distância entre eles dentro de cada um dos sete grupos que foram formados no Dendograma de Jaccard, em que foram avaliados quanto à eficiência na fixação simbiótica de nitrogênio em experimento realizado em ambiente semi-protegido, em vasos de "Leonard" (Vincent, 1970), esterilizados. Os vasos continham uma mistura de vermiculita e areia na 
proporção de 2:1, na parte superior, e, na parte inferior, solução nutritiva (Sarruge, 1975) isenta de nitrogênio, com pH 6,0, e esterilizada em autoclave a $120^{\circ} \mathrm{C}$ por 15 minutos. Em cada vaso, foram colocadas cinco sementes de Vigna unguiculata, previamente desinfestadas, utilizando-se cinco vasos por tratamento.

A inoculação dos vasos foi realizada utilizando-se uma alíquota de $10 \mathrm{~mL}$ do caldo de culturas de cada estirpe de isolado estudado, crescidas em meio levedura-manitol, incubadas a $28^{\circ} \mathrm{C}$. Nesta avaliação, foi utilizada para comparação estirpe recomendada 03-84-6/2010 UFLA (SEMIA 6461). Além dos tratamentos inoculados, foram conduzidos dois tratamentos controle, um sem adição de nitrogênio e outro com adição de alíquotas de $1 \mathrm{ml}$ da solução de $\mathrm{NH}_{4} \mathrm{NO}_{3}\left(20 \mathrm{~g} \mathrm{~L}^{-1}\right)$, equivalente a $100 \mathrm{~kg}$ de $\mathrm{N} \mathrm{ha}^{1}$, adicionadas a cada 15 dias, ao longo do experimento. Após quinze dias de desenvolvimento, foi realizado o desbaste das plantas, deixando-se duas por vaso. $\mathrm{O}$ experimento foi conduzido com cinco repetições por tratamento.

Ao final do período de 40 dias, a parte aérea foi separada do sistema radicular, acondicionada em sacos de papel e submetida à secagem em estufa a $65^{\circ} \mathrm{C}$, durante três dias. Uma vez seca, a parte aérea foi pesada, em seguida moída para a determinação química do acúmulo de nitrogênio no tecido, segundo metodologia descrita por Tedesco et al. (1995). Os nódulos foram destacados das raízes, contados e colocados em estufa a $65^{\circ} \mathrm{C}$, durante três dias, para secagem. Foram avaliados o número e a massa seca de nódulos. O índice de eficiência relativa de fixação de Nitrogênio relativa (EFR) dos isolados foi calculado através da fórmula proposta por Brockwell et al. (1966).

Ao final, os dados da caracterização morfológica dos isolados foram utilizados para geração de dendrograma de similaridade de Jaccard. A análise de variância e o teste de comparação de médias de Scott e Knott ao nível de $1 \%$ de probabilidade foram realizados com o programa computacional Genes. E a análise de correlação de Pearson foi utilizado o software $\mathrm{JM}{ }^{\circledR}$ versão 10.0.0.

\section{Resultados e Discussão}

De acordo com os resultados obtidos após os 40 dias, pode-se constatar que todos os tratamentos estavam com nódulos, com exceção da segunda repetição do tratamento sem nitrogênio. Este resultado não seria positivo se o trabalho fosse para avaliar características das plantas como para eficiência de nitrogênio e demais parâmetros que necessitam das plantas, tendo em vista que não haveria controle; entretanto, para fins de seleção e caracterização microbiológica este resultado não vem a ser considerado negativo. Esta contaminação dos tratamentos controle pode ter sido ocasionada pelo tempo de autoclavagem dos substratos, em vista que a areia antes de autoclavar já estaria contaminada com bactérias do grupo rizóbio que sobreviveram a autoclagem de $121^{\circ} \mathrm{C}$ a 90 minutos ou causados pelas condições do ambiente já que o experimento foi conduzido em condições semi-controladas se assemelhando a condições de campo. Conforme Mazaro et al. (2007), que avaliaram o tempo de autoclavagem do substrato com intervalo, constataram que duas autoclavagens de 30 minutos a $121^{\circ} \mathrm{C}$ com um intervalo entre as duas de 24 horas, possibilita a completa esterilização do substrato, onde os microrganismos que resistiram a primeira exposição ao calor e pressão, não suportam uma segunda exposição.

Contudo, os resultados coletados ao final da caracterização morfológica dos isolados (Tabela 2) demonstraram um total de 37 isolados provenientes dos nódulos das plantas mais a estirpe recomendada, que foram agrupados em oito grupos geneticamente semelhantes de acordo com o dendrograma (Figura 1).

Podemos notar que os solos de áreas agrárias do município de Areia (PB) possuem diversidade de rizóbios, mesmo aqueles que as características se aproximam geneticamente da estirpe recomendada como podemos notar os isolados de UFPB Vu 01; UFPB Vu 36 e UFPB Vu 35. Podendo estes apresentar qualidades ótimas de nodulação nas plantas e consequentemente eficiência de nitrogênio, o que também não descarta a possibilidade de outros genótipos mais distantes geneticamente serem eficientes igual à estirpe recomendada ou até melhor que ela, levando em consideração ao clima e solo que estes já estão adaptados. 
Caracterização e seleção de rizóbios nativos de solos paraibanos associados à Vigna unguiculata ...

Souza e Martins

Tabela 2 Caracterização morfológica dos isolados

\begin{tabular}{|c|c|c|c|c|c|c|c|c|c|c|c|c|}
\hline ID - UFPB & Loc. $^{1}$ & Cresc. (dias) & Tam. (mm) & Forma $^{2}$ & Elevação & Bordo & Superfície & Consistência & Conf. $^{3}$ & Cor $^{4}$ & Det. óptico 5 & Teste Gram \\
\hline UFPB Vu 01 & ML & 2 & 3 & $\overline{\mathrm{Ci}}$ & 4 & Inteira & Lisa & Pastosa & $\mathrm{Gr}$ & Sc & Op & $\mathrm{Ne}$ \\
\hline UFPB Vu 02 & ML & 2 & 3 & $\mathrm{Ci}$ & 4 & Inteira & Lisa & Pastosa & $\mathrm{Gr}$ & $\mathrm{Sc}$ & Op & $\mathrm{Ne}$ \\
\hline UFPB Vu 03 & ML & 2 & 2,7 & $\mathrm{Ci}$ & 3 & Inteira & Lisa & Pastosa & $\mathrm{Gr}$ & $\mathrm{Sc}$ & Op & $\mathrm{Ne}$ \\
\hline UFPB Vu 04 & ML & 1 & $<1 \mathrm{~mm}$ & Po & 3 & Inteira & Lisa & Pastosa & $\mathrm{Gr}$ & $\mathrm{Sc}$ & Tra & $\mathrm{Ne}$ \\
\hline UFPB Vu 05 & ML & 1 & 1,1 & $\mathrm{Ci}$ & 3 & Inteira & Lisa & Aquosa & $\mathrm{Gr}$ & $\mathrm{Sc}$ & Op & $\mathrm{Ne}$ \\
\hline UFPB Vu 06 & ML & 1 & $<1 \mathrm{~mm}$ & Po & 3 & Inteira & Lisa & Pastosa & $\mathrm{Gr}$ & $\mathrm{Sc}$ & Op & $\mathrm{Ne}$ \\
\hline UFPB Vu 07 & ML & 1 & $<1 \mathrm{~mm}$ & Po & 3 & Inteira & Lisa & Aquosa & $\mathrm{Gr}$ & $\mathrm{Sc}$ & Op & $\mathrm{Ne}$ \\
\hline UFPB Vu 08 & ML & 2 & 3,7 & $\mathrm{Ci}$ & 4 & Inteira & Lisa & Pastosa & $\mathrm{Gr}$ & $\mathrm{Cr}$ & Tra & $\mathrm{Ne}$ \\
\hline UFPB Vu 09 & DSER & 1 & $<1 \mathrm{~mm}$ & $\mathrm{Ir}$ & 6 & Denteado & Rugosa & Pastosa & $\mathrm{Ir}$ & $\mathrm{Sc}$ & Tra & $\mathrm{Ne}$ \\
\hline UFPB Vu 10 & DSER & 1 & $<1 \mathrm{~mm}$ & Po & 3 & Inteira & Lisa & Pastosa & $\mathrm{Gr}$ & $\mathrm{Sc}$ & Op & $\mathrm{Ne}$ \\
\hline UFPB Vu 11 & DSER & 1 & 4 & $\mathrm{Ci}$ & 4 & Inteira & Lisa & Gomosa & $\mathrm{Gr}$ & $\mathrm{Sc}$ & Tra & $\mathrm{Ne}$ \\
\hline UFPB Vu 12 & DSER & 1 & $<1 \mathrm{~mm}$ & Po & 6 & Denteado & Rugosa & Pastosa & $\mathrm{Ir}$ & $\mathrm{Sc}$ & Ter & $\mathrm{Ne}$ \\
\hline UFPB Vu 13 & DSER & 1 & 4 & $\mathrm{Ci}$ & 3 & Inteira & Lisa & Gomosa & $\mathrm{Gr}$ & $\mathrm{Sc}$ & Tra & $\mathrm{Ne}$ \\
\hline UFPB Vu 14 & DSER & 3 & $<1 \mathrm{~mm}$ & Po & 1 & Inteira & Lisa & Aquosa & $\mathrm{Gr}$ & $\mathrm{Sc}$ & Op & $\mathrm{Ne}$ \\
\hline UFPB Vu 15 & DSER & 1 & 2,7 & $\mathrm{Ci}$ & 3 & Inteira & Lisa & Pastosa & $\mathrm{Gr}$ & $\mathrm{Sc}$ & Op & $\mathrm{Ne}$ \\
\hline UFPB Vu 16 & DSER & 1 & $<1 \mathrm{~mm}$ & Po & 3 & Inteira & Lisa & Pastosa & $\mathrm{Gr}$ & $\mathrm{Sc}$ & Tra & $\mathrm{Ne}$ \\
\hline UFPB Vu 17 & DSER & 1 & $<1 \mathrm{~mm}$ & Po & 1 & Inteira & Lisa & Pastosa & $\mathrm{Gr}$ & $\mathrm{Sc}$ & Tre & $\mathrm{Ne}$ \\
\hline UFPB Vu 18 & DSER & 1 & 3,5 & $\mathrm{Ci}$ & 4 & Inteira & Lisa & Gomosa & $\mathrm{Gr}$ & $\mathrm{Sc}$ & Op & $\mathrm{Ne}$ \\
\hline UFPB Vu 19 & DSER & 1 & $<1 \mathrm{~mm}$ & Po & 3 & Inteira & Lisa & Pastosa & $\mathrm{Gr}$ & $\mathrm{Sc}$ & Tra & $\mathrm{Ne}$ \\
\hline UFPB Vu 20 & DSER & 1 & 5 & $\mathrm{Ci}$ & 3 & Inteira & Lisa & Pastosa & $\mathrm{Gr}$ & $\mathrm{Sc}$ & Op & $\mathrm{Ne}$ \\
\hline UFPB Vu 21 & $\mathrm{Ch}$ & 1 & $<1 \mathrm{~mm}$ & $\mathrm{Ir}$ & 3 & Denteado & Rugosa & Pastosa & En & $\mathrm{Sc}$ & Op & $\mathrm{Ne}$ \\
\hline UFPB Vu 22 & $\mathrm{Ch}$ & 1 & 2 & $\mathrm{Ci}$ & 3 & Inteira & Lisa & Pastosa & $\mathrm{Gr}$ & $\mathrm{Sc}$ & Op & $\mathrm{Ne}$ \\
\hline UFPB Vu 23 & $\mathrm{Ch}$ & 1 & $<1 \mathrm{~mm}$ & $\mathrm{Ir}$ & 6 & Denteado & Rugosa & Pastosa & $\mathrm{Ir}$ & $\mathrm{Sc}$ & Ter & $\mathrm{Ne}$ \\
\hline UFPB Vu 24 & $\mathrm{Ch}$ & 1 & 2 & $\mathrm{Ci}$ & 3 & Inteira & Lisa & Pastosa & $\mathrm{Gr}$ & $\mathrm{Sc}$ & Op & $\mathrm{Ne}$ \\
\hline UFPB Vu 25 & $\mathrm{Ch}$ & 1 & $<1 \mathrm{~mm}$ & Po & 1 & Denteado & Rugosa & Pastosa & En & $\mathrm{Sc}$ & Op & $\mathrm{Ne}$ \\
\hline UFPB Vu 26 & $\mathrm{Ch}$ & 1 & $<1 \mathrm{~mm}$ & $\mathrm{Ci}$ & 4 & Inteira & Lisa & Pastosa & $\mathrm{Gr}$ & $\mathrm{Sc}$ & Op & $\mathrm{Ne}$ \\
\hline UFPB Vu 27 & In & 1 & 1,1 & $\mathrm{Ci}$ & 4 & Inteira & Lisa & Pastosa & $\mathrm{Gr}$ & $\mathrm{Sc}$ & Op & $\mathrm{Ne}$ \\
\hline UFPB Vu 28 & In & 1 & $<1 \mathrm{~mm}$ & Po & 6 & Denteado & Rugosa & Pastosa & En & $\mathrm{Sc}$ & Tra & $\mathrm{Ne}$ \\
\hline UFPB Vu 29 & In & 1 & 1,1 & $\mathrm{Ci}$ & 4 & Inteira & Lisa & Pastosa & $\mathrm{Gr}$ & $\mathrm{Sc}$ & Op & $\mathrm{Ne}$ \\
\hline UFPB Vu 30 & In & 1 & $<1 \mathrm{~mm}$ & Po & 1 & Inteira & Lisa & Pastosa & Gr & $\mathrm{Sc}$ & Tra & $\mathrm{Ne}$ \\
\hline UFPB Vu 31 & In & 1 & $<1 \mathrm{~mm}$ & $\mathrm{Ci}$ & 4 & Inteira & Lisa & Pastosa & $\mathrm{Gr}$ & Ro & Op & $\mathrm{Ne}$ \\
\hline UFPB Vu 32 & In & 1 & $<1 \mathrm{~mm}$ & Po & 4 & Inteira & Lisa & Pastosa & $\mathrm{Gr}$ & Ro & Op & $\mathrm{Ne}$ \\
\hline UFPB Vu 33 & In & 1 & $<1 \mathrm{~mm}$ & Po & 6 & Denteado & Rugosa & Pastosa & En & $\mathrm{Sc}$ & Tra & $\mathrm{Ne}$ \\
\hline UFPB Vu 34 & In & 2 & $<1 \mathrm{~mm}$ & Po & 3 & Inteira & Lisa & Pastosa & $\mathrm{Gr}$ & $\mathrm{Sc}$ & Op & $\mathrm{Ne}$ \\
\hline UFPB Vu 35 & In & 2 & 1,1 & Po & 3 & Inteira & Lisa & Pastosa & $\mathrm{Gr}$ & $\mathrm{Cr}$ & Op & $\mathrm{Ne}$ \\
\hline UFPB Vu 36 & In & 2 & 2,5 & $\mathrm{Ci}$ & 4 & Inteira & Lisa & Pastosa & $\mathrm{Gr}$ & $\mathrm{Cr}$ & Op & $\mathrm{Ne}$ \\
\hline
\end{tabular}

${ }^{1}$ Localização - ML (Mata Limpa), DSER (Departamento de Solos e Engenharia Rural, Ch (Chã de Jardim) e In (Inoculante);

${ }^{2}$ Forma - Ci (circular), Po (pontiforme) e Ir (irregular);

${ }^{3}$ Configuração - Gr (granular), Ir (irregular) e En (enrugada);

${ }^{4} \mathrm{Cor}-\mathrm{SC}$ (sem cor), Cr (creme) e Ro (rosa);

${ }^{5}$ Detalhe óptico - Op (opaca), Tra (Translúcida) e Ter (Transparente);

${ }^{6}$ Teste Gram - NE (Negativa). 


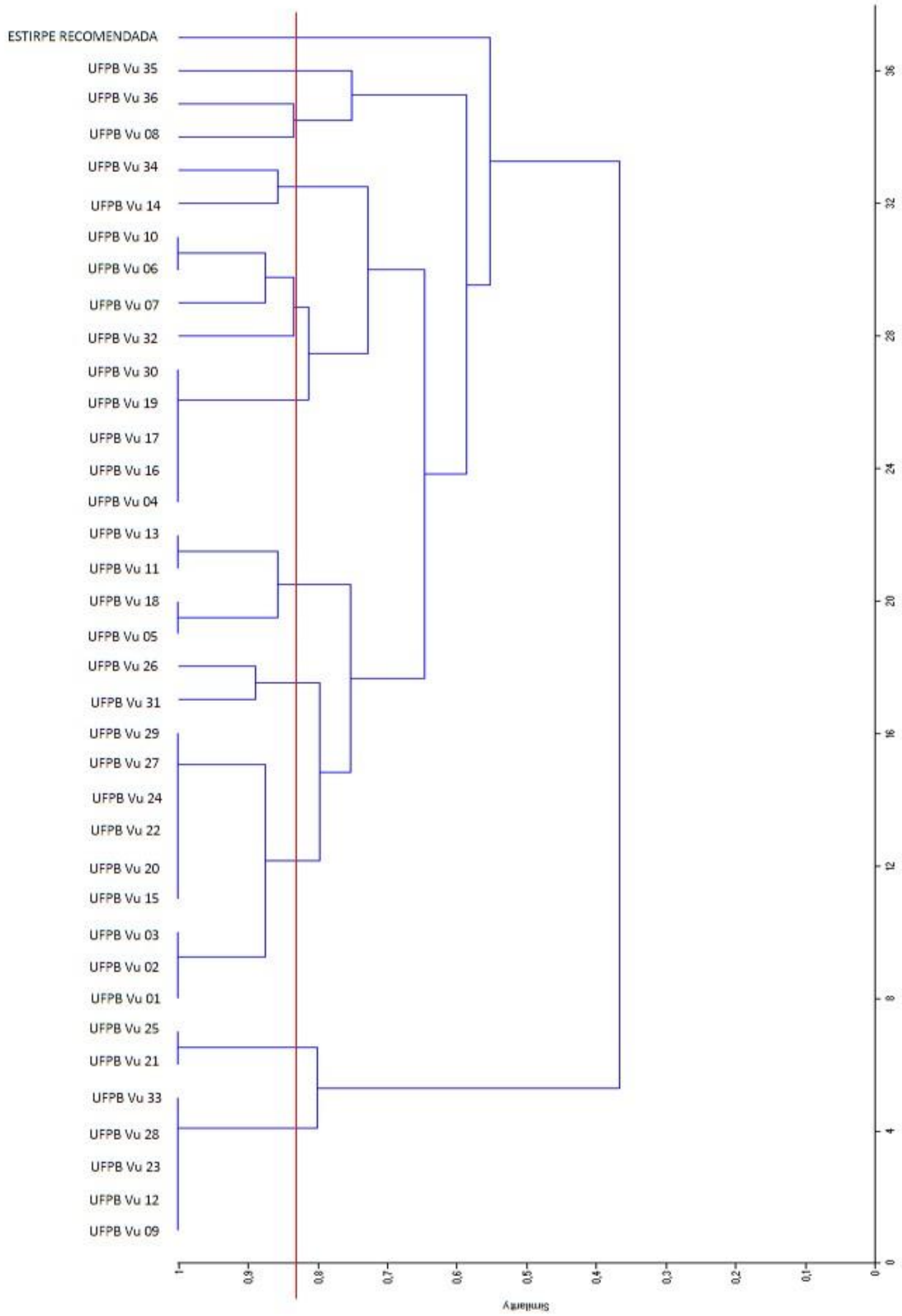

Figura 1 Dendograma de Jaccard com o agrupamento dos grupos de isolado.

Agropecuária Técnica, Areia-PB, v. 40, n. 3-4, p. 71-81, 2019 
Quanto as características morfológicas avaliadas dos isolados (Tabela 2), de acordo com Martins et al, (1997) que diz que as colônias de rizóbio em meio YMA são diferentes umas das outras com base no tempo de crescimento, sendo estas classificadas como rápidas aquelas que apresentam um crescimento moderado e abundante até 3 dias; intermediárias que crescem entre 4 a 5 dias; lentas aquelas que possuem um crescimento de 6 até 9 dias; e as muito lentas que iniciam o seu crescimento a partir de 10 dias. Os isolados encontrados neste experimento apresentaram crescimento rápido onde até três dias as colônias já estavam formadas. Com isso pode-se contestar os resultados encontrados por Sprent (1994), Barnet \& Catt (1991) segundo estes em experimento com bactérias isoladas de nódulos de raízes de Acacia spp., o crescimento rápido das bactérias fixadoras de nitrogênio é influenciado de acordo com a sua localização geográfica, onde as de crescimento rápido são obtidas somente em zonas áridas como as de seus estudos na Autrália em Fowler's Gap; e no presente estudo o trabalho foi desenvolvido em área denomina de brejo paraibano, devido as características edoclimáticas. De acordo com (Bowen, 1956; Lange, 1961) as leguminosas australianas são tradicionalmente semelhantes ao caupi quanto a nodulação por estirpes de Bradyrhizobium spp.

Segundo Norris (1965), estirpes de crescimento rápido são originárias de regiões temperadas, e as de crescimento lento se originam em regiões do trópico úmido. Outros autores como Tam \& Broughton (1981) e Martins (1997); Xavier et al. (1998); Freitas et al. (2007); Santos et al., (2007) e Medeiros et al., (2009), corroboram com o presente estudo, tendo em vista que os autores mencionam que rizóbio de crescimento rápido são mais frequentes em regiões semi-áridas, onde está característica seria uma estratégia para sobrevivência em um meio ao um ambiente seco.

Xavier et al. (2007) também corroboram com esses resultados supracitados para $\mathrm{o}$ fator temperatura, num experimento que testando o crescimento de estirpes de rizóbio provenientes de três regiões Zona da Mata, Agreste e Sertão em feijão-caupi, encontraram resultados positivos para crescimento em altas temperaturas, acima de $40^{\circ}$. Pode-se notar que não há um consenso sobre os fatores que interferem na simbiose entre plantas e rizóbios.

Para dar prosseguimento ao experimento onde selecionou os isolados dos quais formaram os tratamentos: 1- Estirpe Recomendada; 2- (UFPB $\mathrm{Vu}$ 08); 3- (UFPB Vu 14); 4- INOCULANTE; 5 (UFPB Vu 02); 6- (UFPB Vu 05); 7- (UFPB Vu 04); 8- (UFPB Vu 31); 9- (UFPB Vu 12). De acordo com a análise de variância houve diferenças significativas para todas as variáveis avaliadas como: Número de nódulos (NN), Massa seca de nódulo (MSN), massa seca de parte aérea (MSPA), Nitrogênio total (Ntotal) e Índice de eficiência relativa de fixação de nitrogênio (ERF), isto indica que os tratamentos, ou seja, os isolados estudados apresentam diferenças estatísticas entre eles que estão além das diferenças morfológicas, mas também que estes influenciam nas características das plantas que é resultado da simbiose entre ambos (Tabela 3 ).

Tabela 3 Análise de variância para número de nódulos (NN), massa seca de nódulos (MSN), massa seca de parte áerea (MSPA) e Índice de eficiência de fixação de nitrogênio (ERF)

\begin{tabular}{ccccccc}
\hline \multirow{2}{*}{ F.V } & & \multicolumn{5}{c}{ Quadrados Médios } \\
& & NN & MSN & MSPA & Ntotal & ERF \\
\hline Tratamento & 10 & $62219,88^{* *}$ & $0,06^{* *}$ & $1,77^{* *}$ & $30,28^{* *}$ & $3381,01^{* *}$ \\
Resíduo & 44 & 4231,45 & 0,00 & 0,27 & 2,37 & 41,86 \\
C.V $(\%)$ & - & 41,16 & 28,81 & 25,16 & 31,51 & 24,00 \\
\hline
\end{tabular}

Total 54

**Significativo a $1 \%$ de probabilidade.

Com os resultados obtidos nas avaliações, pode-se notar que os isolados tiveram um grande poder de indução de nodulação no feijão-caupi, com médias a partir de 68 nódulos por vaso até aproximadamente 342 , onde os tratamentos 3 e 4 obtiveram os maiores valores respectivamente 305 e 343 nódulos e o menor valor foi do isolado 3 , com isso podemos notar também que como

Agropecuária Técnica, Areia-PB, v. 40, n. 3-4, p. 71-81, 2019

https://doi.org/10.25066/agrotec.v40i3-4.44892 
esperado a massa seca de nódulos tende a aumentar quanto maior for a quantidade de nódulos, só apresentaram resultados superiores de MSN os isolados que obtiveram acima de 150 nódulos, onde pode-se notar que os maiores valores foram dos isolados $3,4,5,8$ e 9 que foram os isolados com valores médios de nódulos superiores a 150 (Tabela 4) de acordo com Ferreira et al. (2011) estes valores são interessantes em bactérias que possam ser usadas como inoculantes, tendo em vista que a manutenção da nodulação durante a fase reprodutiva pode resultar num aumento da produtividade.

Tabela 4 Número de nódulos (NN) e da massa seca de nódulos (MSN), e produção de massa seca (MSPA) e eficiência relativa de fixação de nitrogênio (ERF) da parte aérea de plantas de feijão-caupi inoculados com isolados de rizóbios e estirpe liberada para produção de inoculantes

\begin{tabular}{lccccc}
\hline \multicolumn{1}{c}{ Tratamentos } & \multicolumn{5}{c}{ Médias } \\
\cline { 2 - 6 } & NN (No/vaso) & MSN (g/vaso) & MSPA (g/vaso) & Ntotal (mg/vaso) & ERF (\%) \\
\hline Nitrogênio & $0,00 \mathrm{~d}$ & $0,00 \mathrm{c}$ & $1,59 \mathrm{c}$ & $2,19 \mathrm{c}$ & $100,00 \mathrm{a}$ \\
Testemunha & $0,00 \mathrm{~d}$ & $0,00 \mathrm{c}$ & $1,00 \mathrm{c}$ & $1,29 \mathrm{c}$ & $0,00 \mathrm{~d}$ \\
1-UFLA 03-84-6/2010 & $125,40 \mathrm{c}$ & $0,17 \mathrm{~b}$ & $2,02 \mathrm{~b}$ & $3,46 \mathrm{c}$ & $19,85 \mathrm{c}$ \\
2-UFPB Vu 08 & $68,00 \mathrm{~d}$ & $0,12 \mathrm{~b}$ & $1,47 \mathrm{c}$ & $3,51 \mathrm{c}$ & $12,46 \mathrm{c}$ \\
3-UFPB Vu 14 & $305,20 \mathrm{a}$ & $0,29 \mathrm{a}$ & $3,20 \mathrm{a}$ & $8,38 \mathrm{a}$ & $31,75 \mathrm{~b}$ \\
4-INOCULANTE & $342,80 \mathrm{a}$ & $0,28 \mathrm{a}$ & $2,67 \mathrm{a}$ & $9,76 \mathrm{a}$ & $37,01 \mathrm{~b}$ \\
5-UFPB Vu 02 & $150,00 \mathrm{~b}$ & $0,22 \mathrm{a}$ & $2,14 \mathrm{~b}$ & $5,46 \mathrm{~b}$ & $20,68 \mathrm{c}$ \\
6-UFPB Vu 05 & $234,20 \mathrm{~b}$ & $0,20 \mathrm{~b}$ & $2,40 \mathrm{~b}$ & $4,66 \mathrm{~b}$ & $19,80 \mathrm{c}$ \\
7-UFPB Vu 04 & $131,60 \mathrm{c}$ & $0,17 \mathrm{~b}$ & $1,88 \mathrm{~b}$ & $4,95 \mathrm{~b}$ & $17,68 \mathrm{c}$ \\
8-UFPB Vu 31 & $211,00 \mathrm{~b}$ & $0,26 \mathrm{a}$ & $2,10 \mathrm{~b}$ & $4,95 \mathrm{~b}$ & $18,73 \mathrm{c}$ \\
9-UFPB Vu 12 & $170,40 \mathrm{c}$ & $0,25 \mathrm{a}$ & $2,13 \mathrm{~b}$ & $4,89 \mathrm{~b}$ & $18,53 \mathrm{c}$ \\
\hline
\end{tabular}

Médias seguidas pelas mesmas letras nas colunas, não diferem estatisticamente entre si pelo teste de Scott-knott a $1 \%$ de probabilidade.

Observou-se que o Inoculante testado obteve resultados positivos o que pode estar relacionado com a sua adaptabilidade ao ambiente do município de Areia-PB, contudo não significa que esta pode ser recomendada para a região tendo em vista que este experimento foi realizado em ambiente semi-controlado, e em campo há fatores externos que podem influenciar em um baixo desempenho, fatores estes que devem ser mais estudados (Tabela 4).

Para os valores de massa seca de parte aérea MSPA obtiveram os maiores valores os tratamentos 3 e $4 \quad(3,20 \mathrm{~g}$ e $2,67 \mathrm{~g})$ respectivamente, os tratamentos com e sem nitrogênio obtiveram valores semelhantes, isto pode estar relacionado ao fato da aplicação de nitrogênio ter sido realizada 2 vezes com intervalos de 15 dias, com alíquotas de solução nitrogenada e a proporção não tenha sido suficiente para promover o acúmulo de biomassa nas plantas, fazendo com que não diferenciasse estatisticamente do controle (Tabela 3).

Para a variável de nitrogênio total apenas os tratamentos 3 e 4 obtiveram as maiores médias, não diferenciando ambas estatisticamente, este resultado demonstra que estes dois isolados são eficientes para estas condições (tabela 5).

Tabela 5 Correlação Pearson entre as variáveis estudadas

\begin{tabular}{cccc}
\hline Interação & Correlação & Contagem & Significância \\
\hline MSN x NN & 0,8692 & 55 & $<, 0001^{*}$ \\
MSPA x NN & 0,8044 & 55 & $<, 0001^{*}$ \\
MSPA x MSN & 0,8229 & 55 & $<, 0001^{*}$ \\
Ntotal x NN & 0,8261 & 55 & $<, 0001^{*}$ \\
Ntotal x MSN & 0,8047 & 55 & $<, 0001^{*}$ \\
Ntotal x MSPA & 0,8102 & 55 & $<, 0001^{*}$ \\
\hline
\end{tabular}


Quanto à eficiência relativa de fixação de nitrogênio (ERF) o tratamento com nitrogênio foi o que obteve maior percentagem, entretanto os tratamentos 3 e 4 foram os que obtiveram as maiores médias $37,01 \%$ e $31,75 \%$, os tratamentos com e sem nitrogênio e a estirpe recomendada obtiveram valores menores, este valor baixo da estirpe que também foi observado nas outras variáveis, e pode estar relacionado com a adaptação dela com o ambiente do município de Areia-PB, os demais tratamentos não apresentaram diferenças significativas entre si. Apesar dos valores de correlação serem baixos eles corroboram com Pimratch et al. (2004b) que fala que durante a fase vegetativa estes resultados são normais.

Com os resultados expressos na tabela 4, pode-se notar que ERF de acordo com a correlação de Pearson não está diretamente relacionada com a quantidade de massa seca de parte aérea do feijão-caupi.

De acordo com a Tabela 5 pode-se notar que nem todas as variáveis possuem interação entre elas, onde nem todas obtiveram resultados significativos. Também se pode notar que o aumento da MSN influencia também no aumento da MSPA, resultados como esse foram encontrados também por Nascimento et al. (2010). Pimratch et al. (2004 a,b) sugerem que o acúmulo da MSPA é a característica mais confiável para seleção de cultivares com maior potencial simbiótico em solos com baixa disponibilidade de nitrogênio.

Entretanto estes resultados não convergem com os encontrados por Nascimento et al., (2010) que segundo os autores a produção de biomassa e de nitrogênio total, foram influenciados pela capacidade de fixação do isolado, resultados com alta correlação envolvendo as variáveis de biomassa seca de parte aérea, nitrogênio total e eficiência relativa em amendoim na zona da mata pernambucana foram encontrados por Silva (2007), apesar dos valores de correlação serem baixos eles corroboram com Pimratch et al. (2004b) que fala que durante a fase vegetativa estes resultados são normais.

\section{Conclusão}

Os solos de zona úmida da Caatinga possuem bactérias fixadoras de nitrogênio e que dentre estes isolados estudados os melhores foram a estirpe encontrada nos solos do município de Areia-PB (UFPB Vu 14) e o Inoculante comercial. Número de nódulos, massa seca de nódulos, massa seca de parte aérea, nitrogênio total estão relacionados entre si. Este estudo ressalta a importância e necessidade do estudo destes microrganismos e o seu potencial na fixação de nitrogênio na cultura do feijão-caupi na Paraíba.

\section{Agradecimentos}

Professora Dra. Fátima Maria de Souza Moreira, do Departamento de Ciência do Solo, Laboratório de Microbiologia do Solo - UFLA por ceder à estirpe recomendada 03-84-6/2010 UFLA (SEMIA 6461).

\section{Referências}

Barnet, Y. M.; Catt, P. C. Distribution and characteristics of root-nodule bacteria isolated from Australian Acacia spp. Plant and Soil, v. 135, n. 1, p. 109-120,1991. https://doi.org/10.1007/BF00014783

Bowen, G. D. Nodulation of legumes indigenous to Queensland. Quesland Journal of Agricultural Science, v.13, p.47-60, 1956.

Brockwell, J.; Hely, F. W; Neal-Smith, C. A. Some symbiotic characteristics of rhizobia responsible for spontaneous, effective field nodulation of Lotus hispidus. Australian Journal of Experimental Agriculture and Animal Husbandry, v. 6, n. 23, p.365-370, 1966. https://doi.org/10.1071/EA9660365

Embrapa. Sistema brasileiro de classificação de solos. $3^{\mathrm{a}}$ ed. Brasília: Embrapa, 2013. 353p.

Ferreira, E. P. B.; Martins, L. M. V.; Xavier, G. R.; Rumjanek, N. G. Nodulação e produção de grãos em feijão-caupi (Vigna unguiculata L. Walp.) inoculado com isolados de rizóbio. Revista Caatinga, v. 24, n. 4, p. 27-35, 2011. https://periodicos.ufersa.edu.br/index.php/caatinga/article /view/2002

Freire Filho, F. R.; Ribeiro, V. Q.; Rocha, M. M.; Silva, K. J. D.; Nogueira, M. S. R.; Rodrigues, E.V. Feijão-caupi no Brasil: produção, melhoramento genético, avanços e desafios. Teresina: Embrapa Meio-Norte, 2011. 84p. 
https://www.alice.cnptia.embrapa.br/bitstream/doc/91683 1/1/feijaocaupi.pdf

Freitas, A. D. S.; Vieira, C. L.; Santos, C. E. R. S.; Stamford, N. P.; Lyra, M. C. C. P. Caracterização de rizóbios isolados de Jacatupé cultivado em solo salino do estado de Pernambuco, Brasil. Bragantia, v. 66, n. 3, p. 497-504, 2007. http://dx.doi.org/10.1590/S000687052007000300017

Hara, F. A. S.; Oliveira, L. A. Características fisiológicas e ecológicas de isolados de rizóbios oriundos de solos ácidos e álicos de Presidente Figueiredo, Amazonas. Acta Amazônica, v. 34, n. 3, p. 343-357, 2007. http://dx.doi.org/10.1590/S0044-59672004000300002

Hungria, M.; Campo, R. J.; Mendes, I. C. A importância do processo de fixação biológica do nitrogênio para a cultura da soja: componente essencial para a competitividade do produto brasileiro. Londrina: Embrapa Soja, 2007. 80p. (Embrapa Soja. Documentos, 283).

Köppen, W. Der geographische system der klimate. In: Koppes, W., Geiger, R. (Ed.) Handbuch der klimatologie. Berlim: Borntrager, 1936. v.1 part c.

Lange, R.T. Nodule bacteria associated with the indigenous Leguminosae of South-Western Australia. Journal of General and Microbiology, v. 26, n. 2, p. 351-359, 1961. https://doi.org/10.1099/00221287-26-2-351

Lieven-Antoniou, C. A.; Whittam, T. S. Specificity in the symbiotic association of Lotus corniculatus and Rhizobium loti from natural populations. Molecular Ecology, v. 6, n. 7, p. 629-639, 1997. https://doi.org/10.1046/j.1365294X.1997.00224.X

Martins, L. M. V.; Neves, M. C. P.; Rumjanek, N. G. Growth characteristics and symbiotic efficiency of rhizobia isolated from cowpea nodules of the north-east region of brazil. Soil Biology and Biochemistry, v. 29, n. 5/6, p. 1005-1010, 1997. https://doi.org/10.1016/S00380717(96)00215-5

Martins, L. M. V.; Xavier, G. R.; Neves, M. C. P.; Rumjanek, N. G. Características relativas ao crescimento em meio de cultura e a morfologia de colônias de "rizóbio". Seropédica: Embrapa Agrobiologia, 1997. 14 p. (Embrapa Agrobiologia. Comunicado Técnico, 19).
Mazarro, S. M.; Guimarães, S. S.; Szepanhuk, V.; Rodrigues, M. B.; Paladini, M. V. Avaliação do tempo de autoclavagem sobre o potencial de contaminação de substrato na técnica de produção em serragem de cogumelos Ganoderma lucidum. Synergismus Scyentifica, n. 2, p. 1-4, 2007. http://revistas.utfpr.edu.br/pb/index.php/SysScy/article/vi ew/143/6

Medeiros, E. V.; Martins, C.M.; Lima, J. A. M.; Fernandes, Y. T. D.; Oliveira, V. R.; Borges, W. L. Diversidade morfológica de rizóbios isolados de caupi cultivado em solos do estado do Rio Grande do Norte. Acta Scientiarum. Agronomy, v. 31, n. 3, p. 529-535, 2009. http://dx.doi.org/10.4025/actasciagron.v31i3.793

Melo, S. R.; Zilli, J. E. Fixação biológica de nitrogênio em cultivares de feijão-caupi recomendadas para o Estado de Roraima. Pesquisa Agropecuária Brasileira, v. 44, n. 9, p. 1177-1183, 2009. http://dx.doi.org/10.1590/S0100-204X2009000900016

Moreira, F. M. M.; Siqueira, J. O. Microbiologia e bioquímica do solo. Lavras: UFLA, 2006. $726 \mathrm{p}$.

Moreira, F. M. S. Bactérias fixadoras de nitrogênio que nodulam Leguminosae. In: Moreira, F. M. S.; Siqueira, J. O.; Brussaard, L. (Ed.). Biodiversidade do solo em ecossistemas brasileiros. Lavras: UFLA, 2008. p.621-680.

Nascimento, L. R. S.; Sousa, C. A.; Santos, C. E. R. S.; Freitas, A. D. S.; Vieira, I. M. M. B.; Sampaio, E. V. S. B. Eficiência de isolados de rizóbios nativos do agreste paraibano em caupi. Revista Brasileira de Ciências Agrárias. v.5, n. $1, \quad$ p. $\quad 36-42 ., \quad 2010$. https://doi.org/10.5039/agraria.v5i1a575

Neves, M. C. P.; Rumjanek, N. G. Diversity and adaptability of soybean and cowpea rhizobia in tropical soils. Soil Biology and Biochemistry, v. 29, n. 5-6, p. 889-895, 1997. https://doi.org/10.1016/S0038-0717(96)00205-2

Norris, D.P. Rhizobium relationships in legumes. Proc. $9^{\text {th }}$ Int. Grassl. Congr. Sao Paulo 2, 1087-1092. 1965. https://www.cabdirect.org/cabdirect/abstract/1965070088 9

Oliveira Júnior, J. O. L. De; Medeiros, R. D. De; Silva, P. R. V. P.; Smiderle, O. J.; Mourão Júnior, M. Técnicas de manejo para o cultivo do caupi em Roraima. Boa Vista: Embrapa 
Roraima, 2002. 19p. (Embrapa Roraima. Circular Técnica, 03).

Pimratch, S. Heritability and correlation for nitrogen fixation and agronomic traits of peanut (Arachis hypogaea L.). Songklanakarin Journal Science Technology, v. 26, n. 3, p. 305-315, 2004. http://www.thaiscience.info/journals/Article/SONG/1046 2436.pdf

Pimratch, S.; Jogloy, S.; Toomsan, B.; Jaisil, P.; Kesmala, T.; Patanothai, A. Evoluation of seven peanut genotypes for nitrogen fixation and agronomic traits. Songklanakarin Journal Science Technology, v. 26, n. 3, p. 295-304, 2004.

http://www.thaiscience.info/Journals/Article/SONG/1046 2434.pdf

Santos, C. E. R. E. S.; Stamford, N. P.; Neves, M. C. P.; Rumjanek, N. G.; Borges, W. L.; Bezerra, R. V. Freitas, A. D. S. Diversidade de rizóbios capazes de nodular leguminosas tropicais. Revista Brasileira de Ciências Agrárias, v. 2, n. 4, p. 249-256, 2007.

Sarruge, J. R. Soluções nutritivas. Summa Phitopathologica, v. 1, n. 3, p. 231- 234, 1975.

Sprent, J.I. Evolution and diversity in the legumerhizobium symbiosis: chaos theory?.Plantand Soil, v. 161, 1994, p. 1-10. https://doi.org/10.1007/BF02183080

Tan, I. K. P.; Broughton, W. H. Rhizobia in tropical legumes. XIII. Biochemical basis of acid and álcali reactions. Soil Biology and Biochemistry, v. 13, n. 5, p. 389-393, 1981. https://doi.org/10.1016/0038-0717(81)90083-3

Tedesco, M. J.; Gianello, C.; Bissani, C.A.; Bohnen, H. \& Volkweiss, S.J. Análise de solo, plantas e outros materiais. 2.ed. Porto Alegre, Departamento de Solos da Universidade Federal do Rio Grande do Sul. 1995. 174p. (Boletim Técnico de Solos, 5).

Thies, J. E.; Bohlool, B. B.; Singleton, P. W. Subgroups of cowpea miscellany: symbiotic specificity within Bradyrhizobium spp. for
Vigna unguiculata, Phaseolus lunatus, Arachis hypogaea, and Macroptilium atropurpureum. Appliedand Environmental Microbiology, v. 57, n. 5, p. 1540-1545, 1991. https://aem.asm.org/content/aem/57/5/1540.full.pdf

Thornthwaite, C. W. An approach towards a rational classification of climate. Geographical Review, v. 38, p. 55-94, 1948. https://www.jstor.org/stable/210739

Vincent, J. M. Manual for the practical study of root nodule bacteria. Blackwell Scientific, v. 12, n. $\quad 5, \quad 1970 . \quad 164$ p. https://doi.org/10.1002/jobm.19720120524

Willems, A. The taxonomy of rhizobia: an overview. Plant and Soil, v. 287, p. 3-14, 2006. https://doi.org/10.1007/978-1-4020-5765-6_1

Xavier, G. R.; Martins, L. M. V.; Neves, M. C. P.; Rumjanek, N. G. Edaphic factors as determinants for the distribution of intrinsic antibiotic resistance in a cowpea rhizobia population. Biology and Fertility of Soils, v. 27, n. 4, p. 386-392, 1998. https://doi.org/10.1007/s003740050

Xavier, G. R.; Martins, L. M. V.; Rumjanek, N. G.; Neves, M. C. P. Tolerância de rizóbio de feijão-caupi à salinidade e à temperatura em condição in vitro. Revista Caatinga, v. 20, n. 4, p. $1-9$, 2007. https://periodicos.ufersa.edu.br/index.php/caatinga/article /view/01

Zhang, W.T.; Yang, J.K.; Yuan, T.Y.; Zhou, J.C. Genetic diversity and phylogeny of indigenous rhizobia from cowpea [Vigna unguiculata (L.) Walp.]. Biology and Fertility of Soils, v. 44, p. 201-210, 2007. https://doi.org/10.1007/s00374-0070196-8

Zilli, J. É.; Valicheski, R. R.; Rumjanek, N. G.; Simões-Araújo, J. L.; Freire Filho, F. R.; Neves, M. C. P. Eficiência simbiótica de estirpes de Bradyrhizobium isoladas de solo do Cerrado em caupi. Pesquisa Agropecuária Brasileira, v. $41, \quad$ n. 5, p. 811-818, 2006. http://dx.doi.org/10.1590/S0100-204X2006000500013 